\title{
APPLICATION OF NMR IN THE INVESTIGATION OF DYNAMIC TAUTOMERISM OF 4(3H)-QUINAZOLINONE SYSTEM
}

\author{
Pham Thi Thanh My, Chu Dinh Kinh*, Thanh Thi Thu Thuy \\ Institute of Chemistry, Vietnamese Academy of Science and Technology
}

Nguyen Ngoc Vinh

Institute of Drug Quality Control, Ho Chi Minh City

Nguyen Thi Phuong Chi

Vietnamese Academy of Science and Technology

Received 06 April 2007

\begin{abstract}
Tautomerism of 4(3H)-quinazolinone system with [(2-hydroxyphenyl)methylene]-2-(4oxoquinazolin-3(4H)-yl) acetohydrazide and $N^{\prime}$-[(1E)-(4-hydroxy-3-methoxyphenyl) methylene]-2-(4-oxoquinazolin-3(4H)-yl)acetohydrazide as two representative compounds was investigated on the basis of ${ }^{1} \mathrm{H}$ NMR method at coalescence with the help of line form programme. The dynamic parameters such as $\mathrm{k}, \mathrm{Ea}, \Delta \mathrm{G}^{*}, \Delta \mathrm{H}^{*}, \Delta \mathrm{S}^{*}$ were fully calculated with high reliability.
\end{abstract}

\section{INTRODUCTION}

In a solution, a molecule may exist in two or more structural forms and continuously transfer from one form to another. NMR is the most useful technique in the investigation of chemical structural interchange. The chemical shift of a nucleus or an equivalent nuclear group depends on the environment. The shape of the signal depends on the interaction of the nucleus with the adjacent nucleus, and the amplitude of the signal is proportional to the concentration. Therefore, any presentation of a compound in a solution, or any change in the concentration, as well as the structural change could be immediately and accurately recorded by NMR.

In this article, we used NMR for investigating the dynamics of the interchange process of tautomer between amide and imidic acid form of [(2-hydroxyphenyl)methylene]-2-(4oxoquinazolin-3(4H)-yl) acetohydrazide and $N^{\prime}$-[(1E)-(4-hydroxy-3methoxyphenyl)methylene]-2-(4-oxoquinazolin-3(4H)-yl)aectohydrazide respectively in $4(3 H)$ quinazolinone system. The conclusion about the characteristics and dynamic properties of the above processes were based on the obtained results of the dynamic parameters of tautomerism.

* Corresponding author e-mail: mailto:kinhcd@ich.ntsc.vn 


\section{OBJECT AND STUDY METHOD}

The investigation object was two synthetic compounds with sign 2 and 4 . Their structures and names were presented in figure 1 and figure 2 . These compounds were synthesized by Dr. Nguyen Ngoc Vinh (Institute of Drug Quality Control - Ho Chi Minh City).

In condition of NMR measurement (in DMSO- $\mathrm{d}_{6}$ solvent), the two above compounds always exist in structural interchange between amide and imidic acid forms in a solution, as in figure 1 and 2. The variation of this structural interchange depends on factors such as concentration, $\mathrm{pH}$ of medium for recording the spectra and temperature.

NMR spectra were recorded on Brucker Avance $500 \mathrm{MHz}$ in the Structure Research DivisionInstitute of Chemistry-Vietnamese Academy of Science and Technology.<smiles></smiles>

$N^{\prime}$-[(1E)-(2-hydroxyphenyl)methylene]-2-(4oxoquinazolin-3(4H)-yl)acetohydrazide

Amide form
$1 Z)-N$-[(1E)-(2-hydroxyphenyl)methylene]-2(4-oxoquinazolin-3(4H)-yl)ethanehydrazonic acid

Fig. 1: Structure and name of compound 2.<smiles>C=COC1=C(O)[In]C(/C=C/NC(=O)Cn2cnc3ccccc3c2=O)=C1</smiles>

$N^{\prime}-[(1 E)$-(4-hydroxy-3-

methoxyphenyl)methylene]-2-(4oxoquinazolin-3(4H)-yl)acetohydrazide

Amide form<smiles>COC1=CC(C=CN=C(O)Cn2cnc3ccccc3c2=O)=IC=C1O</smiles>

(1Z) $-N-[(1 E)-(4-h y d r o x y-3-$ methoxyphenyl)methylene]-2-(4oxoquinazolin-3(4H)-yl)ethanehydrazonic acid

Fig. 2: Structure and name of compound 4.

The line form programme was supplied by Dr. Thanh Thi Thu Thuy, based on simplification of Bloch equation.

The dynamics of structural interchange was investigated by two effects: Structural interchange under the impact of solution $\mathrm{pH}$ and temperature.

The dynamic parameters were calculated by a combination of two methods: line form method and coalescence temperature method.

At coalescence (when two signals overlapped without observation of valley between two signals), the velocity constant and activated free enthalpy of interchange process can be 
calculated as follow $[1,2]$ :

$$
\begin{gathered}
k_{c}=\frac{1}{\sqrt{2}} \pi \cdot \Delta v=2,22 \cdot \Delta v \\
\Delta G_{c}=19,1 T_{c}\left(10,32+\log \left(T_{c} / k_{c}\right)\right.
\end{gathered}
$$

From the above values, parameters such as Activated Enthalpy $\left(\Delta \mathrm{H}^{*}\right)$, Activated Entropy $\left(\Delta \mathrm{S}^{*}\right)$ and Activated Energy (Ea) can be calculated by following equations [4, 5]:

$$
\begin{gathered}
\ln k=-\frac{E a}{R} T+\ln A \\
\Delta H^{*}=E a-R . T \\
\Delta G^{*}=\Delta H^{*}-T . \Delta S^{*}
\end{gathered}
$$

Where:

$\mathrm{T}_{\mathrm{c}}: \quad$ coalescence temperature

$\mathrm{k}$ : velocity constant

$\mathrm{k}_{\mathrm{c}}$ : velocity constant at coalescence

$\Delta v$ : Width of peak at half height in coalescence, equivalent to frequency difference $(\mathrm{Hz})$ of two signals in non interchange stage (in low temperature).

$\Delta \mathrm{G}^{*}$ : activated free enthalpy

$\Delta \mathrm{H}^{*}$ : activated enthalpy

$\Delta \mathrm{S}^{*}$ : activated entropy

The line form programme had an important role in prediction and navigation of coalescence temperature, so preliminary research was remarkably shortened.

The above method was applied to intermediate interchange process starting from two peaks broadened and moved closer until they overlapped. The equations used to calculate dynamic parameters were applied to special cases, in which two tautomers had equal concentration. Therefore, the experimental measurements should be carried out in a condition controlling equilibrium of two isomers in solution with equal concentration [1].

\begin{tabular}{|c|c|c|c|c|c|c|c|c|c|c|c|c|}
\hline No.C & 2 & 5 & 6 & 7 & 8 & 1 ' & 2 ' & 5 , & 8 ' & 9' & 10 ' & $11^{\prime}$ \\
\hline Amide & $\begin{array}{c}8.337 \\
(\mathrm{~s})\end{array}$ & \multirow{2}{*}{$\begin{array}{c}8.133 \\
(\mathrm{~m})\end{array}$} & \multirow{2}{*}{$\begin{array}{c}7.564 \\
(\mathrm{~m})\end{array}$} & \multirow{2}{*}{$\begin{array}{c}7.849 \\
(\mathrm{~m})\end{array}$} & \multirow{2}{*}{$\begin{array}{c}7.713 \\
(\mathrm{~m})\end{array}$} & $\begin{array}{c}5.168 \\
(\mathrm{~s})\end{array}$ & $\begin{array}{c}11.710 \\
(\mathrm{~s})\end{array}$ & $\begin{array}{c}8.318 \\
(\mathrm{~s})\end{array}$ & \multirow{2}{*}{$\begin{array}{c}6.878 \\
(\mathrm{~m})\end{array}$} & \multirow{2}{*}{$\begin{array}{c}7.253 \\
(\mathrm{~m})\end{array}$} & \multirow{2}{*}{$\begin{array}{c}6.878 \\
(\mathrm{~m})\end{array}$} & $\begin{array}{c}7.696 \\
(\mathrm{~m})\end{array}$ \\
\hline $\begin{array}{c}\text { Imidic } \\
\text { acid }\end{array}$ & $\begin{array}{c}8.301 \\
\text { (s) }\end{array}$ & & & & & $\begin{array}{c}4.771 \\
\text { (s) }\end{array}$ & $\begin{array}{c}12.085 \\
(\mathrm{~s})\end{array}$ & $\begin{array}{c}8.413 \\
\text { (s) }\end{array}$ & & & & $\begin{array}{c}7.519 \\
(\mathrm{~m})\end{array}$ \\
\hline
\end{tabular}

\section{RESULTS AND DISCUSSION}

\subsection{The dynamic properties of compound 2}

The NMR data of compound 2 were illustrated in Table 1.

Table 1: NMR data of compound 2. 
In NMR spectrum, the simultaneous existence of amide and imidic acid form in the solution was clearly observed. The variety of the above components depends on the $\mathrm{pH}$ of NMR recording medium, so the $\mathrm{pH}$ of compound 2 solution was differently adjusted (by addition of the suitable amount of NaOD to the above solution). The results showed that while $\mathrm{pH}$ varied (increased or decreased), the amplitude of imidic acid peak always increased. The result is consistent with the theory of isomer interchange in the presence of acid or base catalyst. The detailed results were illustrated in Table 2.

Table 2: Variety of content (\%) of amide and imidic acid form while pH varied.

\begin{tabular}{lcccc}
\hline \multicolumn{1}{c}{$\mathbf{p H}$} & $\mathbf{7 , 0}$ & $\mathbf{7 , 5}$ & $\mathbf{8 , 0}$ & $\mathbf{8 , 5}$ \\
\cline { 1 - 3 } & & 61 & 57 & 51 \\
Amide & 80 & 39 & 43 & 49 \\
\hline
\end{tabular}

The dynamic research of equilibrium varied by temperature was carried out for the sample solution having $\mathrm{pH} 8$ with nearly equal content of amide and imidic acid form (about $51 \%$ and 49\%).

The line form programme has an important role in the field of dynamic research by NMR method. From input parameter is the amplitude of two peak corresponding to two forms of the same proton (symbolized by content of two form) and the difference of chemical shift of two peaks $(\Delta v)$, the direct results of programme is peak form corresponding to life time $\tau$ of nucleus. Since then, the users can obtain the indirect results, which are velocity constant, coalescence temperature as well as dynamic parameters by simplified calculation through equations $(1) \div(5)$.

We set up line form spectrum for compound 2 at 3 positions including single peak of proton 2 , proton 1' and proton 5'. The obtained results are shape of peaks corresponding to life time $\tau$ of nucleus. From life time $\tau$, the corresponding temperature can be calculated. Therefore, in other words the line form programme gives results, which are shape of spectrum signal corresponding to the spectrum recording temperature. The calculated results of compound 2 were illustrated in Table 3 .

Table 3: The coalescence temperature values obtained from theoretical calculation of compound 2 .

\begin{tabular}{cccc}
\hline Position & $\mathbf{2}$ & $\mathbf{1}$ & $\mathbf{5}$, \\
\hline$\Delta v(\mathbf{H z})$ & 8,5 & 198,5 & 38,0 \\
$\mathbf{k}_{\mathbf{c}}\left(\mathbf{s}^{-\mathbf{1}}\right)$ & 18,87 & 440,67 & 84,36 \\
$\mathbf{T}_{\mathbf{c}}(\mathbf{K})$ & 337 & 396 & 363 \\
\hline
\end{tabular}

For checking the above theoretical results, ${ }^{1} \mathrm{H}$ NMR spectrum of compound 2 were recorded at 5 points of temperature (within safety temperature of NMR instrument): $300 \mathrm{~K}, 337 \mathrm{~K}, 340 \mathrm{~K}$, $353 \mathrm{~K}$ and $363 \mathrm{~K}$. For more convenient visual comparison, the theoretical spectra corresponding to life time $\tau$ of nucleus and experimental spectra corresponding to spectrum recording temperatures were depicted in Figure 3, 4 and 5. 


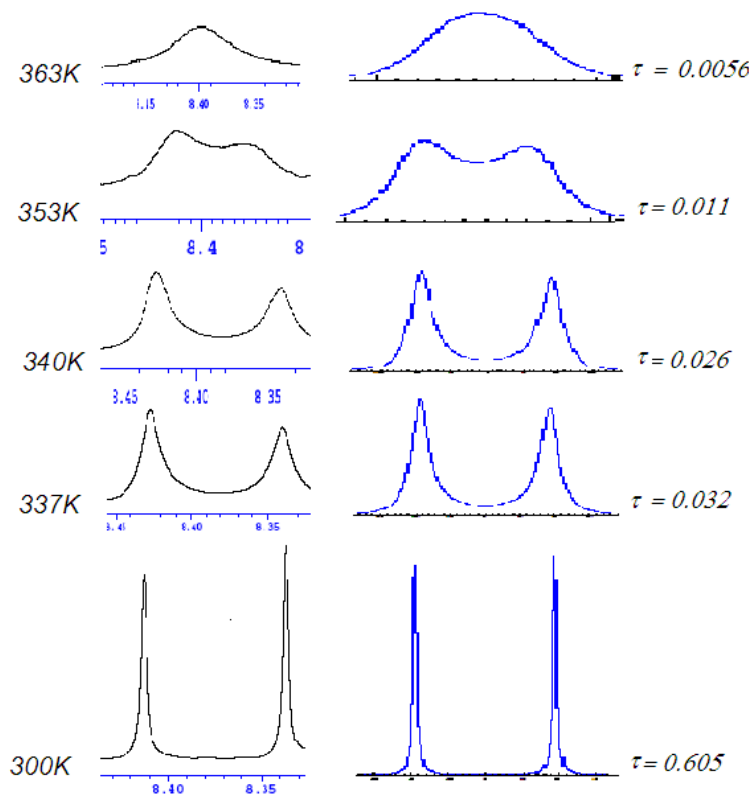

Fig. 3: The theoretical signal (corresponding to $\tau$ ) and the experimental signal (corresponding to $T)$ of proton 5 '.

The perfect homogeneity between the two shapes of theoretical and experimental signal can be observed. This proved that the line form programme was set up accurately and had a great significance in the dynamic research by NMR method.
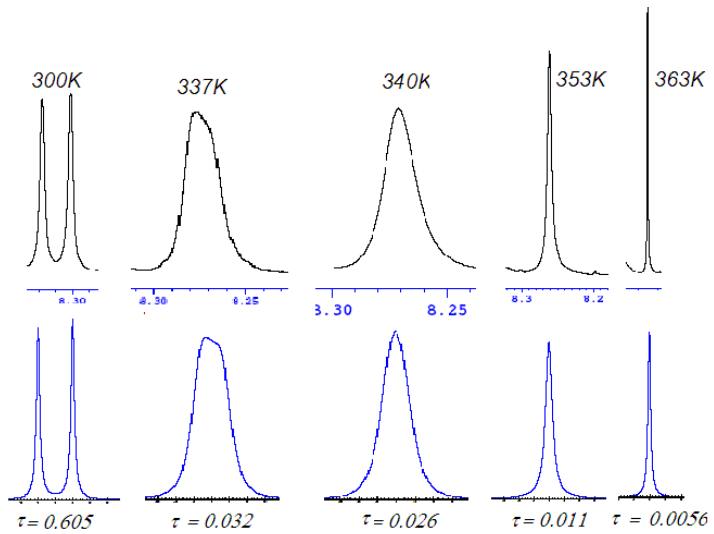

Fig. 4: The theoretical signal (corresponding to $\tau$ ) and the experimental signal (corresponding to $T$ ) of proton 2.

For high energy process, if the unification stage takes place in high temperature, the spectrum recording will meet much difficulty, and sometimes it can not be carried out. In this case, the simple and effective measure is to use the line form programme. Take proton 1' of compound 2 for instance, the temperature increase for spectrum recording approached $363 \mathrm{~K}$ (figure 5), but the unification still did not happened. $392 \mathrm{~K}$ is the unification temperature based on the calculation from the line form programme. From the point of unification temperature, the 
dynamic parameters were easily calculated and the exact conclusions about dynamic properties of tautomerism as well as tautomer properties were given.

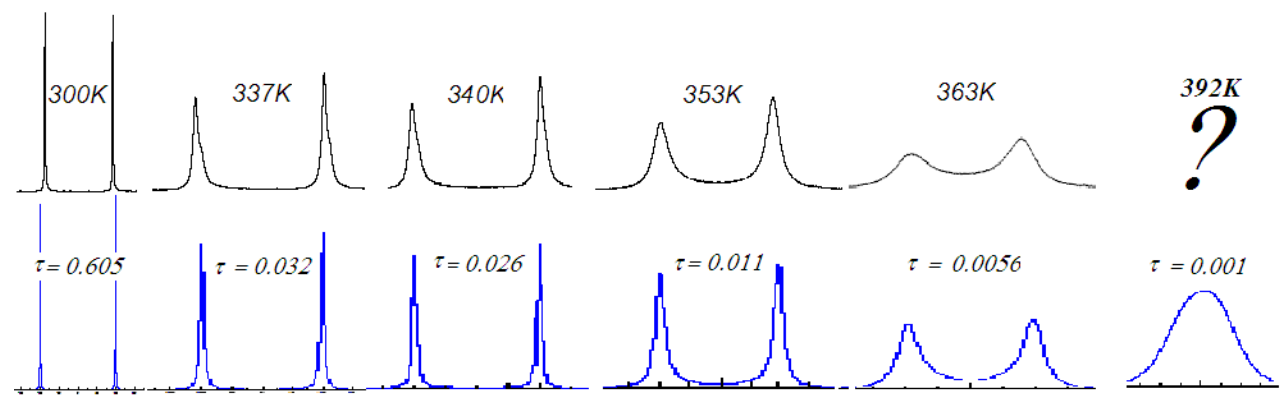

Fig, 5: The theoretical signal (corresponding to $\tau$ ) and the experimental signal (corresponding to $T$ ) of proton 1 '.

The dynamic properties were calculated at suitable unification temperature time by equation (1) $\div$ (5) with values listed in Table 4 .

Table 4: The dynamic parameters of tautomerism.

\begin{tabular}{|c|c|c|c|c|c|c|}
\hline $\mathbf{T c}(\mathbf{K})$ & $\boldsymbol{\Delta} \mathbf{v}(\mathbf{H z})$ & $\mathbf{k}\left(\mathbf{s}^{\mathbf{- 1}}\right)$ & $\mathbf{E a}(\mathbf{K c a l} / \mathbf{m o l})$ & $\begin{array}{c}\Delta \mathbf{G}^{*} \\
(\mathbf{K c a l} / \mathbf{m o l})\end{array}$ & $\begin{array}{c}\Delta \mathbf{H}^{*} \\
(\mathbf{K c a l} / \mathbf{m o l})\end{array}$ & $\begin{array}{c}\Delta \mathbf{S}^{*} \\
(\mathbf{c a l} / \mathbf{m o l} . \mathbf{K})\end{array}$ \\
\hline 340 & 8.5 & 18.87 & & 18.02 & 15.30 & -11.6 \\
\hline 363 & 38 & 84.36 & \multirow{2}{*}{15.98} & 18.21 & 15.26 & -8.13 \\
\hline 392 & 198.5 & 440.67 & & 18.39 & 15.20 & -8.14 \\
\cline { 5 - 7 } & & & &
\end{tabular}

\subsection{The dynamic characteristics of compound 4}

The NMR data of compound 4 were given in Table 5.

Table 5: The NMR data of compound 4.

\begin{tabular}{|c|c|c|c|c|c|c|c|c|c|c|c|c|c|}
\hline No.C & 2 & 5 & 6 & 7 & 8 & $1 '$ & 2 ' & 5 , & 8 & $9^{\prime}$ & $10^{\prime}$ & $11^{\prime}$ & $\begin{array}{c}\mathrm{O}- \\
\mathrm{CH}_{3}\end{array}$ \\
\hline Amide & $\begin{array}{c}8.381 \\
(\mathrm{~s})\end{array}$ & \multirow{2}{*}{$\begin{array}{c}8.161 \\
(d) \\
J=8\end{array}$} & \multirow{2}{*}{$\begin{array}{c}7.574 \\
(\mathrm{t}) \\
\mathrm{J}_{1}=\mathrm{J}_{2} \\
=7.5\end{array}$} & \multirow{2}{*}{$\begin{array}{c}7.862 \\
(\mathrm{~m})\end{array}$} & \multirow{2}{*}{$\begin{array}{c}7.722 \\
(\mathrm{~d}) \\
\mathrm{J}=8\end{array}$} & $\begin{array}{c}5.223 \\
(\mathrm{~s})\end{array}$ & $\begin{array}{c}11.622 \\
(\mathrm{~s})\end{array}$ & $\begin{array}{c}7.952 \\
(\mathrm{~s})\end{array}$ & $\begin{array}{c}7.330 \\
(\mathrm{~d}) \\
\mathrm{J}=1.5\end{array}$ & $\begin{array}{c}3.838 \\
\text { (s) }\end{array}$ & \multirow{2}{*}{$\begin{array}{c}9.522 \\
(\mathrm{~s})\end{array}$} & $\begin{array}{c}6.848 \\
(\mathrm{~d}) \\
\mathrm{J}=8\end{array}$ & $\begin{array}{c}7.126 \\
(\mathrm{dd}) \\
\mathrm{J}_{1}=1.5 \\
\mathrm{~J}_{2}=8\end{array}$ \\
\hline $\begin{array}{l}\text { Imidic } \\
\text { acid }\end{array}$ & $\begin{array}{c}8.367 \\
(\mathrm{~s})\end{array}$ & & & & & $\begin{array}{c}4.773 \\
(\mathrm{~s})\end{array}$ & $\begin{array}{c}11.667 \\
\text { (s) }\end{array}$ & $\begin{array}{c}8.123 \\
(\mathrm{~s})\end{array}$ & $\begin{array}{c}7.275 \\
(\mathrm{~d}) \\
\mathrm{J}=1.5\end{array}$ & $\begin{array}{c}3.806 \\
\text { (s) }\end{array}$ & & $\begin{array}{c}6.836 \\
(d) \\
\mathrm{J}=8\end{array}$ & $\begin{array}{c}7.106 \\
(\mathrm{dd}) \\
\mathrm{J}_{1}=1.5 \\
\mathrm{~J}_{2}=8\end{array}$ \\
\hline
\end{tabular}

${ }^{1} \mathrm{H}$ NMR spectrum of compound 4 was recorded in DMSO- $\mathrm{d}_{6}$ in the presence of equilibrium interchange agent. The two equilibrium interchange agents used in this case were NaOD solution and $\mathrm{CF}_{3} \mathrm{COOD}$ solution. The detailed data were given in Table 6 . 
Table 6: Content (\%) variation of two tautomers (amide and imidic acid form) of compound 4, while $\mathrm{pH}$ changed.

\begin{tabular}{ccccccccc}
\hline \multicolumn{1}{c}{$\mathbf{p H}$} & $\mathbf{4 , 0}$ & $\mathbf{5 , 0}$ & $\mathbf{5 , 5}$ & $\mathbf{7 , 0}$ & $\mathbf{7 , 5}$ & $\mathbf{7 , 7}$ & $\mathbf{8 , 0}$ & $\mathbf{8 , 5}$ \\
$\begin{array}{c}\text { Form } \\
\text { Amide }\end{array}$ & 44 & 55 & 61 & 79 & 64 & 61 & 56 & 51 \\
Imidic acid & 56 & 45 & 39 & 21 & 36 & 39 & 44 & 49 \\
\hline
\end{tabular}

The content determination was based on signal of $\mathrm{CH}_{2}$ group at position 1'. The value at $\mathrm{pH} 7.0$ is corresponding to the spectrum recorded in DMSO- $\mathrm{d}_{6}$ without interchange agent. The value at $\mathrm{pH}<7.0$ is corresponding to the spectrum recorded in DMSO- $\mathrm{d}_{6}$ with the addition of interchange agent as $\mathrm{CH}_{3} \mathrm{COOD}$ solution. $\mathrm{pH}>7.0$ is corresponding to spectrum recorded in DMSO- $\mathrm{d}_{6}$ with addition of interchange agent as $\mathrm{NaOD}$ solution.

We can see that both agents had impact on the equilibrium of transfer to imidic acid, and the content increase of imidic acid form was proportionate to the added amount of the interchange agent.

The dynamic research of equilibrium change vs. temperature was carried out for the sample solution at $\mathrm{pH} 8.5$ with relatively equal content of amide and imidic acid form (about $51 \%$ and $49 \%$, respectively).

The line form spectrum of compound 4 gave the singlet peak of proton at position 2, 1', 5', 7' and $\mathrm{OCH}_{3}$, as well as the calculation results of the suitable coalescence temperature at the same time. The results were illustrated in Table 7.

Table 7: The coalescence temperature values of compound 4 obtained by theoritical calculation.

\begin{tabular}{cccccc}
\hline Position & $\mathbf{2}$ & $\mathbf{1}$ & $\mathbf{5}$, & $\mathbf{7}$ & $\mathbf{O}^{-} \mathbf{C H}_{\mathbf{3}}$ \\
\hline$\Delta \boldsymbol{v}(\mathbf{H z})$ & 2,0 & 215,5 & 69,5 & 61,0 & 15,5 \\
$\mathbf{k}_{\mathbf{c}}\left(\mathbf{s}^{-\mathbf{1}}\right)$ & 4,44 & 478,41 & 154,29 & 135,42 & 34,41 \\
$\mathbf{T}_{\mathbf{c}}(\mathbf{K})$ & $\mathbf{3 1 7 , 4 3}$ & 388,87 & 368,83 & $\mathbf{3 6 6 , 6 5}$ & $\mathbf{3 4 5 , 2 4}$ \\
\hline
\end{tabular}

The spectrum recording was carried out at 3 points of coalescence, which according to the above theoretical calculation were at $317 \mathrm{~K}, 345 \mathrm{~K}$ and $367 \mathrm{~K}$. In addition, supplemental spectrum at $320 \mathrm{~K}, 355 \mathrm{~K}$ and $360 \mathrm{~K}$ were recorded for clear observation of the interchange process stages.

The experimental results were consistent with theoretical calculation. The coalescence of two signals of proton at position 2 and 7 ' exactly took place at two points of the above calculated temperature ( $317 \mathrm{~K}$ and $367 \mathrm{~K})$.

The signal of $\mathrm{OCH}_{3}$ proton had chemical shift at $\delta=3.761 \mathrm{ppm}$ (amide form) and $3.730 \mathrm{ppm}$ (imidic acid form), these two signals were near the signal of water trace in spectrum recording solution $(\delta=4.234 \mathrm{ppm}$ at $300 \mathrm{~K})$. In recording process with variation of temperature, the peak of water did not appear at a fixed position, but transferred to the high field while temperature increased (Table 8). The undesired thing was at $345 \mathrm{~K}$ (the theoretically calculated coalescence temperature of $\mathrm{OCH}_{3}$ at position 7'), the signal of water trace was completely overshadowed by 
the signal of $\mathrm{OCH}_{3}$. Therefore, whether coalescence truly happened or not at this temperature was not determined.

Table 8: Variation of chemical shift of water peak vs. temperature in solution $(p H=8.5)$.

\begin{tabular}{cccccccc}
\hline $\mathrm{T}(\mathrm{K})$ & 300 & 317 & 320 & 345 & 355 & 360 & 367 \\
\hline$\square(\mathrm{ppm})$ & 4.234 & 4.050 & 4.033 & 3.790 & 3.711 & 3.680 & 3.692 \\
\hline
\end{tabular}

Figures 6, 7, 8, 9 gave the stages of tautomerism obtained from experimental and theoretical calculation.
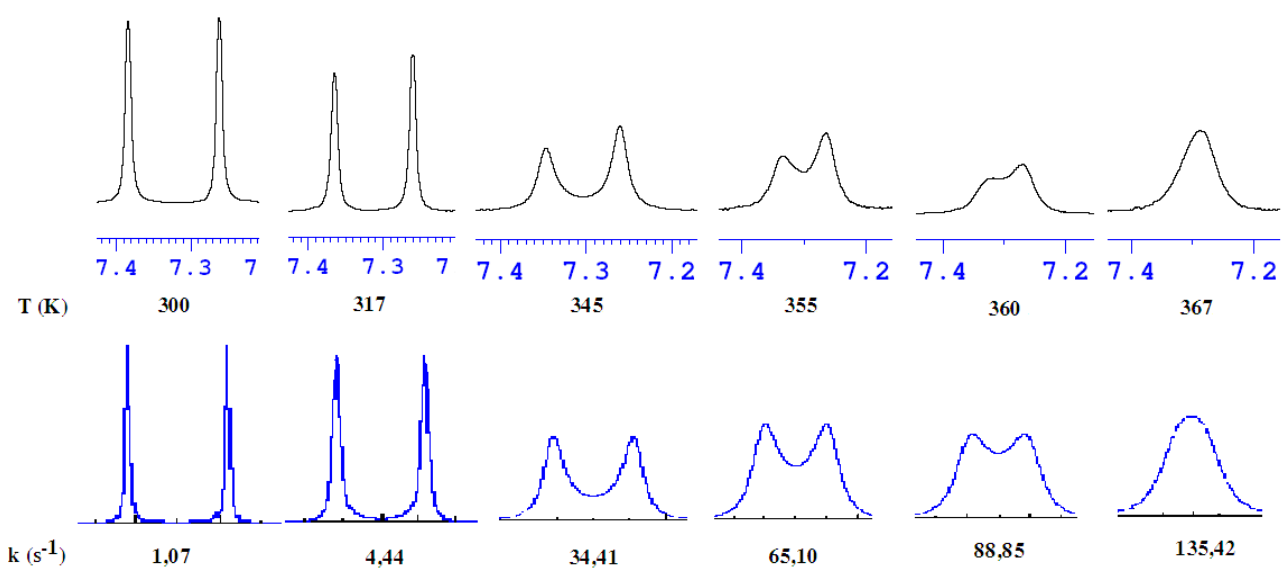

Fig. 6: Theoretical signal (corresponding to $k$ ) and experimental signal (corresponding to T) of proton 5 ' in compound 4.

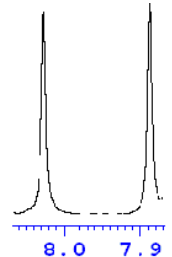

$\mathbf{T}(\mathbf{K})$

300

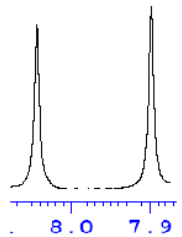

317
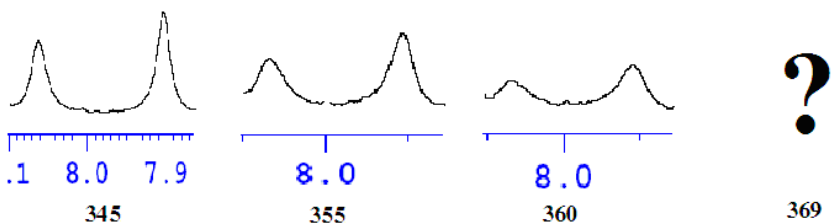

369
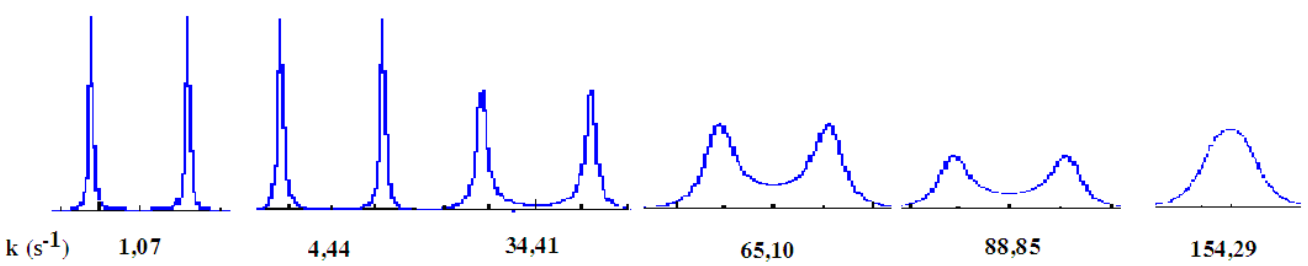

Fig. 7: Theoretical signal (corresponding to $k$ ) and experimental signal (corresponding to T) of proton 7' in compound 4. 
$\mathbf{T}(\mathbf{K})$
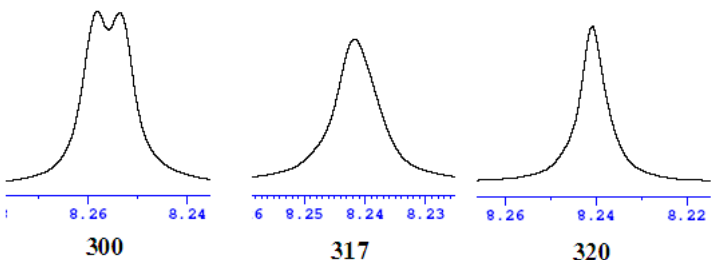

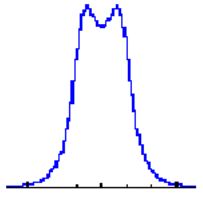

1,07

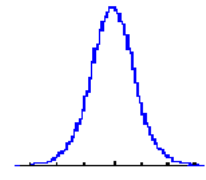

4,44

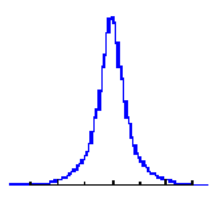

5,62
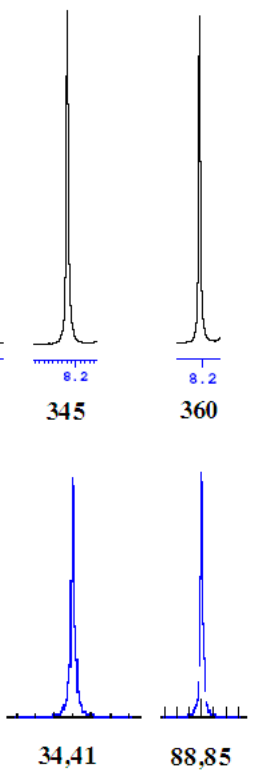

Fig. 8: Theoretical signal (corresponding to $k$ ) and experimental signal (corresponding to $T$ ) of proton 2 of compound 4.

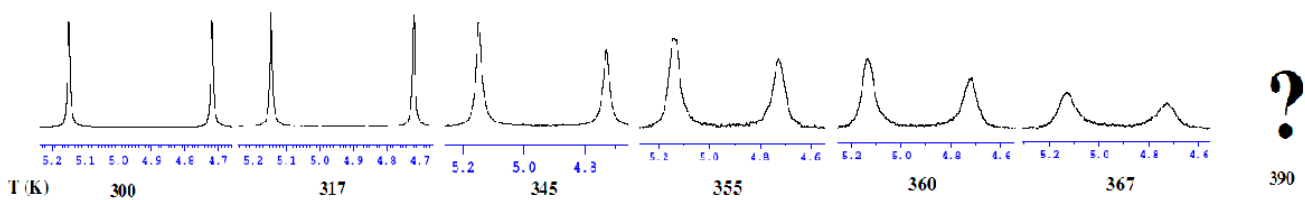

317

367

390

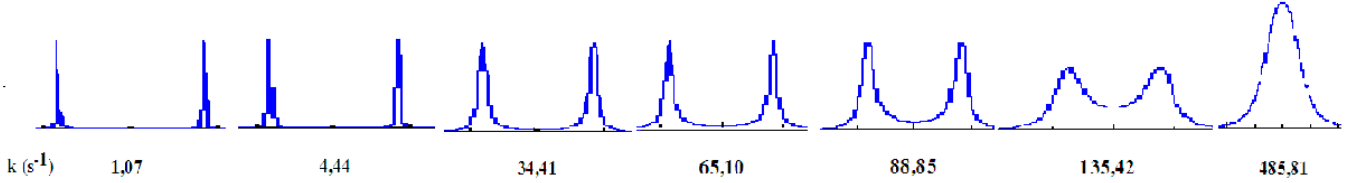

Fig. 9: Theoretical signal (corresponding to $k$ ) and experimental signal (corresponding to $T$ ) of proton l' of compound 4.

Likewise compound 2, the dynamic parameters of compound 4 were calculated following equation $2 \div 5$. The results were illustrated in Table 9 .

Table 9: The dynamic parameters of tautomerism of compound 4.

\begin{tabular}{|c|c|c|c|c|c|c|}
\hline Te (K) & $\begin{array}{c}\Delta v \\
(\mathrm{~Hz})\end{array}$ & $\begin{array}{l}\mathbf{k} \\
\left(\mathbf{s}^{-1}\right)\end{array}$ & $\begin{array}{c}\text { Ea } \\
(\text { Kcal/mol })\end{array}$ & $\begin{array}{c}\Delta \mathbf{G}^{*} \\
(\mathrm{Kcal} / \mathrm{mol})\end{array}$ & $\begin{array}{c}\Delta \mathbf{H}^{*} \\
(\mathrm{Kcal} / \mathrm{mol})\end{array}$ & $\begin{array}{c}\Delta S^{*} \\
(\mathrm{cal} / \mathrm{mol} . \mathrm{K})\end{array}$ \\
\hline 317 & 2,0 & 4,44 & \multirow{5}{*}{15,81} & 17,63 & 13,80 & $-6,34$ \\
\hline 345 & 15,5 & 34,41 & & 17,85 & 12,94 & $-8,32$ \\
\hline 367 & 61,0 & 135,42 & & 18,03 & 12,76 & $-8,31$ \\
\hline 369 & 69,5 & 154,29 & & 18,04 & 12,74 & $-8,32$ \\
\hline 390 & 215,5 & 485,81 & & 18,23 & 12,57 & $-8,31$ \\
\hline
\end{tabular}


Observing the results obtained from Table 2 and 9, we saw that the calculated values of velocity constant of both compound 2 and 4 were located in $10-10^{5} \mathrm{~s}^{-1}$ range, and the activated energy of compound 2 and 4 were $15.81 \mathrm{kcal} / \mathrm{mol}(66.09 \mathrm{~kJ} / \mathrm{mol})$ and $18.98 \mathrm{kcal} / \mathrm{mol}(66.8 \mathrm{~kJ} / \mathrm{mol})$ respectively. This allowed us to confirm that the structural interchange was consistent with research method by ${ }^{1} \mathrm{H}$ NMR $(1 \leq \mathrm{k} \leq 105 \mathrm{~s}-1 ; 10 \leq \mathrm{Ea} \leq 100 \mathrm{~kJ} / \mathrm{mol})$. This was an indirect result for us to confirm that the occurring process followed the primary equilibrium mechanism [3].

The dynamic parameters of compound 2 and 4 were not significantly different $(\Delta \mathrm{Ea}=0.17$ $\mathrm{kcal} / \mathrm{mol}$ ). These results were reasonable because the two compounds were structurally similar. The difference was only $\mathrm{OCH}_{3}$ group. Therefore, from these results we can see that $\mathrm{CH}_{3}$ group in particular and other substitution groups on aromatic ring in general, may not greatly impact the dynamics of structural interchange. Therefore, based on the research results of the two mentioned compounds, we can predict the results for other compounds having similar structures with high precision.

From the above figures we found that at $300 \mathrm{~K}$, the amplitude of signal of two forms was equal, i.e. the content of two components amide and imidic acid of both compounds 2 and 4 is almost equal (about $49 \%$ and $51 \%$ ). However, the above content equality decreased when temperature increased; there was a proportion between temperature and content of imidic acid component. This allowed us to confirm that tautomer equilibrium between the two components depended on temperature. The imidic acid formation process was endothermic. However, in this work we did not go deep into this subject.

\section{The error of research results:}

To validate the error of the obtained dynamic parameter is very important. In the research progress, the factors that may cause the error of the results were:

\section{The error in determining coalescence temperature.}

We can meet the error of $\pm 2^{\circ} \mathrm{C}$ in determining coalescence temperature. This can cause error of about $10-15 \%$ for velocity constant.

\section{The error in the application of calculation expression.}

The expression of velocity constant at coalescence as following:

$$
k_{c}=\frac{1}{\sqrt{2}} \pi \cdot \Delta v=2,22 . \Delta v
$$

Where: $\Delta v$ is difference of chemical shift between two peaks at non-interchange stage. This value was determined from experimental spectrum at $300 \mathrm{~K}$. Some signals at this temperature belonged to non-interchange stage, but other signals at this temperature were transferred to a slow stage. However, in reference document [2], according to the author Eberhard Briemaier the value of above $\Delta v$ will be calculated at a slow interchange stage. This contradiction originated from the fact that the value of above $\Delta v$ was not almost varied in the non-interchange stage as well as in the slow interchange stage, and the loss of precision really happened from intermediate interchange stage when the signals overlapped so that the determination of chemical shift of each peak was very difficult. Therefore, the error $\Delta v$ was removed.

As mentioned above, the important thing was that the energy parameters were proportional to lnk, so the error of $\mathrm{k}$ had a small impact on the energy error. The calculation showed that the error $10 \%, 25 \%$ and $100 \%$ of $\mathrm{k}$ only caused the corresponding error of $0.06,0.1$ and 0.4 $\mathrm{kcal} / \mathrm{mol}$ of $\Delta \mathrm{G}^{*}$ respectively. 
In addition, the expressions of coalescence temperature method were based on simplification of Block equation applied for chemical interchanges with equal content. In the research process, the condition of equal content of the two forms was broken as equilibrium interchanged while temperature changed. This thing caused the errors, which were difficult in validation of the research results.

\section{The systematic error of instruments used in research process}

\section{CONCLUSION}

The nuclear magnetic resonance method was an effective method in the investigation of interchange process dynamics. According to coalescence temperature method, the velocity constants corresponding to each time point of coalescence can be calculated. While coalescence of some signals in a molecule occurred, the activated parameters were calculated on equation Eyring or Arrhenius. The calculated results had high precision.

The determination of coalescence temperature was carried out by line form programme. This helps to reduce the number of spectra recorded in the temperature variation, especially in case the temperature exceeded the allowance limit of the instrument.

\section{REFERENCES}

1. Michinori Oki (1985), Applications of Dynamic NMR spectroscopy to organic Chemistry, Deerfield Beach, Florida, pp. 1- 37.

2. Eberhard Breitmaier (2002), Structure elucidation by NMR in Organic chemistry, John Wiley \& son, Ltd, pp. 1- 65.

3. Harald Günther (1992), NMR Spektroskopic, Georg Thieme Verlag Stuttgart. New York, pp. 303- 346 .

4. Muriel Sebband, Pascal Palmas (2005), Tautomerism and 1H, 13C and 15N NMR spectral assignments of some nitro derivatives of malonic acid diamide, Magnetic Resonance in Chemistry, 43, pp. 563- 566 .

5. Stepan Sklenak, Yitzhak Apeloig (2000), Equilibria of simple thioenol/ thiocarbonyl pairs. A theoretical study, J. Chem. Soc, 2 , pp. 2269- 2274.

6. Nguyen Ngoc Vinh, Truong The Ky (2002), Synthesis of some derivatives of 4(3H)quinazolinone with biological activity from $\mathrm{N}$-acetylanthranilic acid, Pharmaceutical Journal ( in Vietnamese), 1, pp. 19- 22.

7. Pham Thi Thanh My, Chu Dinh Kinh, Nguyen Ngoc Vinh et al., (2005), Several NMR characteristics of $4(3 \mathrm{H})$ - Quinazolinone system, Advance in natural science, 6, 2, pp. 191203. 